\title{
Direct effects on instrumental performance of outcome revaluation by drive shifts
}

\author{
BARBARA E. SHIPLEY and RUTH M. COLWILL \\ Brown University, Providence, Rhode Island
}

\begin{abstract}
In three experiments the sensitivity of instrumental responding to revaluation of the instrumental outcome in the absence of experience with the revalued outcome was examined. Hungry rats were trained to make one response for food pellets and a different response for sucrose liquid. In Experiment 1, these responses were tested in extinction when the animals were either thirsty or hungry. A significant preference for the sucrose-trained response was observed in the test conducted under thirst but not in that conducted under hunger. In Experiments 2 and 3, the effect of experience with sucrose under thirst on the magnitude of this preference was explored. Following training of the instrumental responses in Experiment 2, half of the animals received presentations of sucrose while they were thirsty; the other half received sucrose while they were hungry. In Experiment 3, the same design was used but these sucrose presentations were made contingent on an instrumental response. Also in Experiment 3, the specificity of the sucrose-response preference to a shift to thirst was examined by testing under increased and decreased levels of hunger. The results of those experiments indicated that the sucrose-response preference is exhibited only under thirst and that exposure to the sucrose under thirst only marginally enhanced that preference. These findings suggest that instrumental responding may be modified by changes in the value of its outcome in the absence of experience with the revalued outcome.
\end{abstract}

Both associative and motivational postconditioning manipulations of the value of an outcome have been used to assay the content of Pavlovian and instrumental associations. Evidence that subsequent performance is appropriate to the new value of the outcome has favored theories asserting that a representation of the outcome is encoded during original learning (see Rescorla, 1982). Little is known, however, about the manner in which such revaluation techniques actuate the change in outcome value. The purpose of the present paper was to examine the conditions necessary for effecting a change in the value of an outcome such that instrumental performance might be sensitive to that changed value.

Associatively induced changes in outcome value depend on Pavlovian pairings of the outcome with either aversive or attractive stimuli. It has been found that performance of an instrumental response may be reduced following pairings of its outcome with a noxious event (e.g., Adams \& Dickinson, 1981; Colwill \& Rescorla, $1985,1986)$ but increased following pairings of its outcome with a desirable event (Rescorla, 1990). Compara-

This research was supported by National Science Foundation Grant BNS 89-15342 to R. M. Colwill. We thank Robert A. Rescorla for many helpful comments on an earlier version of the manuscript and Charles Collyer for helpful comments on statistical analyses. Correspondence concerning this article should be addressed to R. M. Colwill, Department of Psychology, Box 1853, Brown University, Providence, RI 02912 .

-Accepted by previous editor, Vincent M. LoLordo ble results have been obtained in studies that use motivationally induced changes in the value of an outcome. Thus, manipulating a biological need state to decrease the outcome value has been found to produce a decrease in responding trained with that outcome (Colwill \& Rescorla, 1985). Similarly, drive manipulations that enhance the value of an outcome have been reported to increase performance of the response trained with that outcome (e.g., Dickinson \& Dawson, 1987, 1988, 1989; Dickinson \& Nicholas, 1983a, 1983b; Khavari \& Eisman, 1971; Krieckhaus \& Wolf, 1968).

These results have been used to support the inference that an instrumental response becomes associated with its outcome ( $\mathrm{R}-\mathrm{O}$ association). Until recently, however, there has been little systematic analysis of the revaluation procedure per se. Rather, it has been implicitly assumed that performance of instrumental responses should adjust automatically to the changed value of their outcomes. However, elaborating upon a suggestion made by Tolman (1949a, 1949b), Dickinson and his colleagues have argued that experience with the changed outcome is necessary for producing behavioral adjustments to the revalued outcome (see Dickinson, 1989; Dickinson \& Balleine, 1994). They note that in many demonstrations of sensitivity of instrumental responses to the current value of their outcomes, the techniques used to alter the value of the outcome involve some exposure to the changed outcome. For example, in studies using satiation to reduce the desirability of the outcome, subjects are repeatedly presented with an initially desirable outcome until they eventually cease consumption of that outcome. 
Of particular relevance to the claim that sensitivity to outcome revaluation depends upon experience with the new value of the outcome are studies showing that instrumental responses remain unaffected by outcome revaluation until experience with the revalued outcome is provided. Dickinson and his colleagues have reported a number of experiments in which revaluation of the outcome as a result of a drive shift produced a selective effect on instrumental performance only after exposure to the revalued outcome had been provided (e.g., Balleine, 1992; Dickinson \& Dawson, 1988, 1989).

The present set of studies was designed to examine further the conditions necessary for outcome revaluation induced by a drive shift to affect instrumental behavior. To maximize detection of a direct impact of outcome revaluation on instrumental performance, the present studies used a choice test rather than the more commonly used single-response test. In this way, any failure to obtain a direct effect of outcome revaluation on instrumental performance could not be attributed to betweensubject variability that might conceal a slight preference for the response whose outcome had been revalued. The general procedure used in all three experiments was modeled after Dickinson and Dawson (1988). Hungry animals were trained to make one response for food pellets and a different response for a sucrose solution. In Experiment 1, these responses were then tested in extinction under hunger or thirst. Thirst induced a significant preference for the sucrose response, whereas hunger did not. Experiments 2 and 3 looked at whether the preference for the sucrose response induced by thirst could be enhanced by prior exposure to sucrose while thirsty. Experiment 2 arranged for free deliveries of sucrose to follow instrumental training. Half the animals received those sucrose presentations while they were thirsty; the other half received sucrose while they were hungry. Experiment 3 used the same design but made the sucrose presentations contingent on an instrumental response during the exposure phase. In addition, Experiment 3 examined the drive specificity of the thirst-induced preference for the sucrose response by testing under increased and decreased levels of food deprivation. It was anticipated that changes in the level of food deprivation would not produce a sucrose-response preference.

\section{EXPERIMENT 1}

The purpose of Experiment 1 was to examine whether instrumental responses were sensitive to a change in the value of their outcomes in the absence of exposure to that new outcome value. In addition to providing a more sensitive choice test of the impact of outcome revaluation on instrumental performance, Experiment 1 incorporated a direct assessment of the effectiveness of the revaluation procedure on the outcome per se. It was important to verify that the revaluation procedure actually induced a change in the relative value of the target outcomes. If the drive shift technique did not induce much of an increase in the value of sucrose relative to pellets, it might well be difficult to detect a reliable preference for the sucrose response during testing. The present study explicitly evaluated the effectiveness of the thirstinduction procedure by measuring responding for either sucrose or pellets under thirst.

The basic design of Experiment 1 is outlined in Figure 1. Hungry rats were trained to make four different instrumental responses (leverpress, chain pull, nose poke, and handle pull). Two of these responses (R1 and R3) earned pellets; the other two (R2 and R4) earned sucrose. Following training, the subjects were given two extinction tests, one when they were hungry and one when they were thirsty. Each test contained a different pair of responses (either R1 and R2 or R3 and R4), one of which had been trained with pellets and the other with sucrose. The question of interest was whether the preference for the sucrose response relative to the pellet response would be greater under thirst than under hunger. Following testing, all animals received two reacquisition tests, one with R1 and R2 and the other with R3 and R4, while thirsty. In each test, both responses were reinforced, one with sucrose and the other with pellets. It was anticipated that responding for sucrose would be greater than responding for pellets.

\section{Method}

\section{Subjects}

The subjects were 16 experimentally naive Holtzman-derived Sprague-Dawley male rats (Harlan Co.) about 100 days old at the start of the experiment. They were housed individually and main-

\begin{tabular}{|c|c|c|c|c|c|c|c|c|c|}
\hline \multicolumn{3}{|c|}{$\begin{array}{l}\text { Training } \\
\text { (Hunger) }\end{array}$} & \multicolumn{4}{|c|}{ Test } & \multicolumn{3}{|c|}{$\begin{array}{c}\text { Reacquisition } \\
\text { (Thirst) }\end{array}$} \\
\hline $\begin{array}{l}\mathbf{R} 1 \\
\mathbf{R} 2\end{array}$ & $\begin{array}{l}-> \\
->\end{array}$ & $\begin{array}{l}\text { Pellet } \\
\text { Sucrose }\end{array}$ & $\begin{array}{l}\text { H: } \\
\text { T: }\end{array}$ & $\begin{array}{l}\mathbf{R} \mathbf{1} \\
\mathbf{R 3}\end{array}$ & $\begin{array}{ll}\mathbf{v} & \mathbf{R} \\
\mathbf{v} & \mathbf{R}\end{array}$ & $\begin{array}{l}\mathbf{R 2} \\
\mathbf{R} 4\end{array}$ & $\begin{array}{l}\mathbf{R} 1 \\
\mathbf{R} 2\end{array}$ & $\begin{array}{l}-> \\
->\end{array}$ & $\begin{array}{l}\text { Pellet } \\
\text { Sucroee }\end{array}$ \\
\hline $\begin{array}{l}\mathbf{R} 3 \\
\mathbf{R}\end{array}$ & $\begin{array}{l}-> \\
->\end{array}$ & $\begin{array}{l}\text { Pellet } \\
\text { sucrose }\end{array}$ & $\begin{array}{l}\text { T: } \\
\text { H: }\end{array}$ & $\begin{array}{l}\mathbf{R} 1 \\
\mathbf{R 3}\end{array}$ & $\begin{array}{l}\mathbf{V} \\
\mathbf{V}\end{array}$ & $\begin{array}{l}\mathbf{R} 2 \\
\mathbf{R} 4\end{array}$ & $\begin{array}{l}\text { R3 } \\
\text { R4 }\end{array}$ & $\begin{array}{l}-> \\
->\end{array}$ & $\begin{array}{l}\text { Pellet } \\
\text { sucrose }\end{array}$ \\
\hline
\end{tabular}

Figure 1. Basic design of Experiment 1: R1, R2, R3, and $R 4$ are instrumental responses (leverpress, chain pull, nose poke, and handle pull); $H$ signifies hunger-drive state and $T$ signifies thirst-drive state. 
tained at $80 \%$ of their ad-lib weights by regulating their daily intake of food. Water was freely available in the home cage except when thirst was induced. Induction of thirst was accomplished by removing the water and providing unlimited access to food for $23 \mathrm{~h}$.

\section{Apparatus}

The apparatus consisted of eight identical Skinner boxes measuring $22.9 \times 20.3 \times 20.3 \mathrm{~cm}$. The two end walls of the chamber were aluminum, and the side walls and ceiling were made of Plexiglas. The floor of the chamber was composed of $0.48-\mathrm{cm}$ stainless steel rods spaced $1.9 \mathrm{~cm}$ apart. Each chamber had a recessed food magazine in the center of one end wall. Sucrose and pellets were delivered through separate tubes inserted through the roof of the food magazine. Each operation of the sucrose dispenser allowed $0.2 \mathrm{ml}$ of $8 \%$ sucrose to flow onto the floor of the food magazine, where it collected in a shallow indentation. Each operation of the pellet dispenser allowed a single $45-\mathrm{mg}$ food pellet (Formula A, P. J. Noyes Co.) to drop onto the floor of the magazine. Each box was equipped with four manipulanda: a lever, a chain pull, a nose poke, and a handle pull. The lever was mounted $2.5 \mathrm{~cm}$ from the right-hand wall of the food magazine. The chain was suspended from a microswitch mounted on the roof of the chamber. The end of the chain was $11 \mathrm{~cm}$ from the grid floor and $3 \mathrm{~cm}$ from the lefthand wall of the food magazine. Located $5.5 \mathrm{~cm}$ directly above the roof of the magazine was the nose-poke manipulandum, which consisted of a circular aperture, $2 \mathrm{~cm}$ in diameter and $1.3 \mathrm{~cm}$ deep. The back of this aperture was covered by a metal plate that operated a microswitch whenever it was depressed. Mounted on the same side of the chamber as the chain but $1.5 \mathrm{~cm}$ below the grid floor was the handle-pull manipulandum. This consisted of a short flat rod protruding $3 \mathrm{~cm}$ into the chamber. Whenever the rod was pulled upward, a microswitch was closed and a response recorded. The same model of microswitch (Unimax Switch Co., 2HBT-1) was used to detect responding on all four manipulanda. Access to these manipulanda was prevented by covering the lever with a metal plate or by retracting it, by retracting the chain through an opening in the ceiling, by inserting a metal cover into the aperture of the nose-poke manipulandum, and by withdrawing the arm of the handle pull. Each Skinner box was enclosed in a sound- and lightresistant shell. Experimental events were controlled and recorded automatically by interfacing (Med Associates) and an XT microprocessor located in an adjoining room.

\section{Procedure}

Magazine training. The subjects received one session of magazine training, in which $1045-\mathrm{mg}$ food pellets (Formula A, P. J. Noyes $\mathrm{Co}$.) followed by $108 \%$ liquid sucrose reinforcers were delivered on a variable-time (VT) 60 -sec schedule. Operation of both the pellet and sucrose dispensers was accompanied by a brief click.

In the present studies, we elected to use an $8 \%$ sucrose solution rather than the $20 \%$ solution used by Dickinson and his colleagues, for two reasons. First, previous research in our laboratory had found this concentration to support levels of responding similar to that obtained with the pellet reinforcer. Second, we wanted to avoid the possibility of using a sucrose concent ration that might, by virtue of its tonicity, act to increase an animal's thirst.

Response training. Following magazine training, all animals were trained to make four different instrumental responses: leverpress, chain pull, nose poke, and handle pull. Initially, each response was trained separately and on different days on a continuous reinforcement (CRF) schedule until 30 reinforcers had been earned. The order of training was leverpress, chain pull, nose poke, and handle pull. For 4 animals, pellets served as the reinforcer for leverpressing and handle pulling and sucrose served as the reinforcer for chain pulling and nose poking; for another 4 subjects, these response-outcome combinations were switched. For 4 further subjects, leverpressing and nose poking earned pellets and chain pulling and handle pulling produced sucrose; for the remaining 4 animals, the opposite response-outcome combinations were arranged. Thus, all animals had two responses trained with the pellet outcome and two with the sucrose outcome.

Responding was then reinforced on a variable-interval (VI) 30 sec schedule with the outcome used in CRF training. Each of the four responses was trained separately on a different day for one 20 min session. The order of training was handle pull, nose poke, chain pull, and leverpress.

All subjects then received five 20-min sessions of concurrent VI training with the lever and chain, intermixed with five 20 -min sessions with the nose-poke and handle-pull manipulanda. Responses were reinforced on independent VI 60 -sec schedules with the restriction that an outcome for one response could be set up only if an outcome for the other response was not already set up. This constraint was intended to ensure responding on both manipulanda, and thus to encourage equivalent levels of conditioning. The order in which the two response pairs were trained was determined by a double-alternation sequence.

One animal failed to make the handle-pull response on Day 1 of concurrent VI training. This response was retrained on both the CRF and VI 30-sec training schedules.

Testing. Each subject received a 10 -min choice extinction test with each pair of responses. One test was conducted while the animals were hungry, and one was conducted while they were thirsty. Thirst was induced by removing the water bottles and providing free access to food for $23 \mathrm{~h}$ prior to the test session. Hunger was induced by giving free access to water but limiting food access so as to maintain the $80 \%$ ad-lib weight. For the first test session, half the animals were hungry and half were thirsty. For half the animals in each of these drive states, the responses tested were the lever and chain; for the remainder, nose poke and handle pull were available. For the second test session, the drive states were switched for all animals and the other pair of responses was tested.

This test cycle was then repeated, but each pair of responses was tested under the other drive state. Thus, the responses tested in the first session under hunger (or thirst) were tested under thirst (or hunger) in the third session. Similarly, the responses tested under hunger (or thirst) in the second session were tested under thirst (or hunger) in the fourth session. The purpose of this second cycle of testing was to provide confirmation of the results of the first test and to equate the treatments of the two pairs of responses.

Drive evaluation. The subjects were first given one 20 -min session of concurrent VI training on each of the two pairs of responses to reestablish responding. The training was conducted while the animals were hungry. To assess the effectiveness of the thirst-induction procedure, the subjects were made thirsty and then given one 10-min concurrent VI training session with each pair of responses. Half of the subjects were tested first with lever and chain; the other half were tested first with nose poke and handle pull. During these tests, conditions were the same as those in the original concurrent training sessions except that the restriction on when reinforcers could be set up was lifted.

\section{Results and Discussion}

Training of the four responses proceeded smoothly. In the final session of concurrent VI training, the mean rate of responding collapsed across response identity was 9.6 responses per minute for pellets and 8.6 responses $/ \mathrm{min}$ for sucrose [Wilcoxon $T(16)=31, p>.05$ ]

The results of greatest interest from the first cycle of extinction testing conducted under thirst and hunger are summarized in Figure 2. Responding established with the pellet outcome (open circles) or the sucrose outcome (filled circles) is shown separately when the animals 


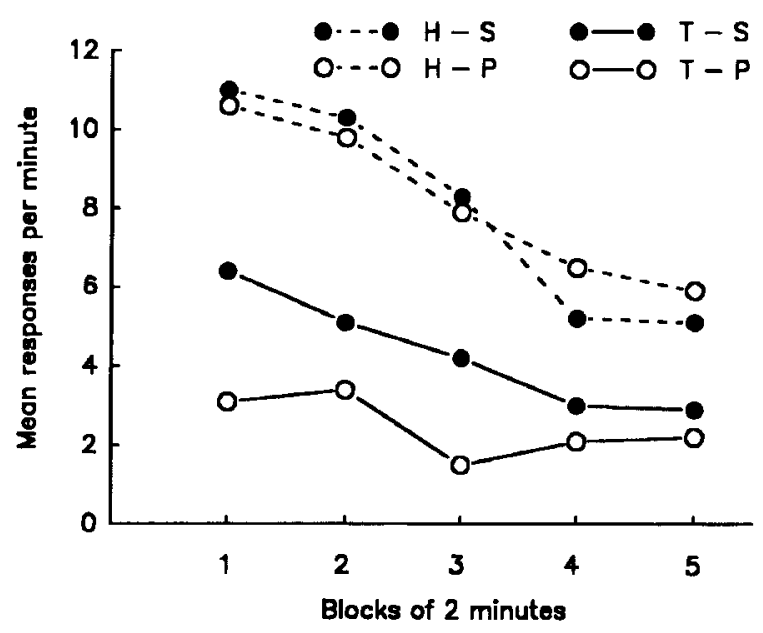

Figure 2. Experiment 1: Mean responses per minute during the first cycle of extinction testing. Responding trained with sucrose (S, filled circles) or pellets ( $P$, open circles) is shown separately when the animals were tested under thirst $(T$, solid lines) or hunger $(H$, dashed lines).

were tested thirsty (solid lines) or hungry (dashed lines) in blocks of $2 \mathrm{~min}$. Although there was generally more responding under hunger than under thirst, responding in both conditions declined over the course of extinction testing. What is more important, however, is the effect of the current drive state on the relative preference for the responses trained with the two outcomes. When the animals were tested hungry, they displayed no preference for the sucrose-trained response; but when they were tested thirsty, they displayed a strong and consistent preference for that response $[T(16)=27, p<.05]$.

The second cycle of testing yielded identical results although overall levels of responding were somewhat lower. Under hunger, there was no significant difference between pellet-trained ( 6.0 responses $/ \mathrm{min}$ ) and sucrosetrained responding ( 4.0 responses $/ \mathrm{min}$ ); under thirst, the rate of sucrose-trained responding (3.5 responses/min) was significantly higher than that of pellet-trained responding (2.3 responses $/ \mathrm{min})[T(16)=27, p<.05]$.

The results of this experiment suggest that experience with the new value of the outcome is not always necessary to influence instrumental performance. Following a shift from hunger to thirst, the rats displayed an immediate preference for the sucrose response. That preference also suggests that the thirst-induction technique was successful in making the sucrose outcome relatively more attractive than the pellet outcome. The results of the drive evaluation tests confirmed that suggestion. The mean rate of responding collapsed across response identity was significantly higher for sucrose (6.9 responses/ $\mathrm{min})$ than for pellets $(4.3$ responses $/ \mathrm{min})[T(16)=22$, $p<.05]$.

The discrepancy between these results and previous reports of failures to obtain a direct effect of outcome revaluation may in part be attributed to the difference in the testing procedures. By allowing a within-subject comparison, the choice test provided a more sensitive index of the impact of outcome revaluation on instrumental responding than would the single-response test. Consistent with this possibility is an apparent tendency toward higher levels of the sucrose-trained response in related experiments by Dickinson and Dawson (1987, 1988, 1989).

\section{EXPERIMENT 2}

In Experiment 1 it was found that an instrumental response might be sensitive to a postconditioning change in the value of its outcome in the absence of experience with that revalued outcome. Experiment 2 was designed to replicate this finding and to examine whether exposure to the revalued outcome would affect the magnitude of that sensitivity. In several studies, Dickinson and his colleagues (e.g., Dickinson \& Dawson, 1988, 1989) have found a thirst-induced preference for the sucrose-trained response following experience with sucrose under thirst. That experience may either precede or follow training of the instrumental responses with sucrose under hunger. It seems plausible that such treatments might augment the sucrose-response preference observed in Experiment 1. By directly providing information about the thirstquenching properties of the sucrose liquid, a more accurate representation of the value of sucrose could be encoded.

Figure 3 illustrates the basic design of Experiment 2. Two responses were trained, one for pellets and one for sucrose. Following training, subjects were made thirsty and given a choice extinction test with the two responses to verify the findings of Experiment 1 . The subjects were then shifted between hunger and thirst on alternating days. Half the subjects were exposed to sucrose on the days when they were thirsty; the other half received equivalent exposure to sucrose on the days when they were hungry. Finally, all subjects were given another choice extinction test while they were thirsty. It was anticipated that the sucrose-response preference would be greater following exposure to sucrose under thirst, inasmuch as that experience with the revalued outcome under the test drive state generates a better representation of the actual value of that outcome.

\section{Method}

\section{Subjects and Apparatus}

Thirty-two experimentally naive male Holtzmanderived Sprague-Dawley rats (Harlan Co.), about 100 days old, served as subjects. The conditions of housing and maintenance were the same as those for Experiment 1 , as was the technique for inducing thirst. The equipment was also the same as that used in Experiment 1.

\section{Procedure}

This experiment was run in two replications $(N=16)$ using identical training and testing procedures. 


\begin{tabular}{|c|c|c|c|}
\hline $\begin{array}{l}\text { Training } \\
\text { (Hunger) }\end{array}$ & $\begin{array}{c}\text { Test } \\
\text { (Thirst) }\end{array}$ & Exposure & $\begin{array}{c}\text { Test } \\
\text { (Thirst) }\end{array}$ \\
\hline RI $\rightarrow$ Pellet & \multirow{2}{*}{$\mathbf{R} \mathbf{1} \mathbf{R} 2$} & Thirst: Sucrose & \multirow{2}{*}{$\mathbf{R} \mathbf{1} \mathbf{v} \mathbf{R}$} \\
\hline R2 -> Sucrose & & Hunger: Sucrose & \\
\hline
\end{tabular}

Figure 3. Basic design of Experiment 2: $R 1$ and $R 2$ are instrumental responses (leverpress and chain pull).

Training. All subjects were magazine trained as in Experiment 1 . They were then trained to leverpress and chain pull. These responses were initially trained in separate sessions on different days. To begin with, each response was programmed to produce a reinforcer until 30 reinforcers had been earned, at which point the session was terminated. The subjects were trained to leverpress on Day 1 and to chain pull on Day 2. For half the subjects, leverpresses earned pellets and chain-pull responses earned sucrose; for the remaining subjects, the response-outcome combinations were switched.

Each response was then reinforced on a VI 30 -sec schedule for two 20-min sessions. The order of training was lever, chain, chain, and lever. These sessions were followed by five 20 -min sessions of concurrent VI training. This training was identical to that described in Experiment 1.

Testing. Following the last session of concurrent VI training, the animals were fed their daily food allowance. Approximately 30 min later, thirst was induced by removing the water from the home cages and providing unlimited access to food. A choice extinction test with the lever and chain was conducted the next day. This session lasted $10 \mathrm{~min}$ and contained no reinforcer deliveries.

Exposure. For the next 10 days, the drive states were shifted between thirst $(\mathrm{T})$ and hunger $(\mathrm{H})$ for all animals. On $\mathrm{T}$ days, half the animals (Exp-T) received one 20-min session in which sucrose was delivered on a VT $60-\mathrm{sec}$ schedule, while the other half (Exp$\mathrm{H})$ remained in their home cages; on $\mathrm{H}$ days, the Exp-H animals were given a 20 -min session consisting of presentations of sucrose on a VT 60 -sec schedule, while the Exp-T subjects remained in their home cages. Following the daily exposure session, the drive states were shifted for all animals. Hunger was induced by returning the water and providing sufficient food to maintain the $80 \%$ adlib weights; thirst was induced by removing the water and providing unlimited access to food for $23 \mathrm{~h}$.

Testing. Following the exposure phase, all subjects were made thirsty and then given a 10 -min choice extinction test with the lever and the chain.

Finally, the subjects were given a 20 -min reacquisition test in which both leverpressing and chain pulling were reinforced on independent VI 60-sec schedules. This test was also conducted while the animals were thirsty and provided additional verification of the success of the thirst-induction technique in changing the relative values of the sucrose and pellet outcomes.

\section{Results and Discussion}

All animals learned to leverpress and chain pull for the pellet and sucrose outcomes. On the last day of concurrent VI training, the mean rate of responding for pellets $(9.9$ responses/min) was significantly higher than that for sucrose $(7.4$ responses $/ \mathrm{min})[T(32)=72.5, z=$ $-3.58, p<.01]$. The reported $z$ scores were calculated using the method suggested by Tate and Clelland (1957).

The results of the first extinction test conducted while the animals were thirsty are plotted in Figure 4. Throughout the session, the subjects displayed a consistent preference for the response trained with sucrose. Com- parison of the overall rates of responding found this difference to be significant $[T(32)=105, z=-2.97, p<$ $.01]$. Thus, the strong preference observed for the pellet response during training under hunger was reversed by switching the deprivation state to thirst. These findings replicate those of Experiment 1 and show that instrumental performance can adjust to a change in outcome value in the absence of exposure to that altered value.

Figure 5 shows the results of the choice extinction test administered after exposure to sucrose when either hungry (dashed lines) or thirsty (solid lines). In each case, responding is shown separately for the sucrose (filled circles) and pellet (open circles) outcomes. Visual inspection of these data reveals a slight elevation of the sucrose-trained response relative to the pellet-trained response in the group exposed thirsty (Exp-T) but not in the group exposed hungry (Exp-H). Analysis of the overall response rates confirmed this impression of the data: In Group Exp-T, the difference between sucrose and pellet responding was not quite significant $[T(16)=$ $31.5, p>.05]$; in Group Exp-H, there was no significant difference. An additional analysis was conducted to assess whether the magnitude of the sucrose preference was greater in Group Exp-T than in Group Exp-H. Sucrose preference ratios were calculated for each subject for the test session by dividing the rate of sucrose responses by the sum of that rate and the rate of pellet responses. A Mann-Whitney $U$ test revealed no significant

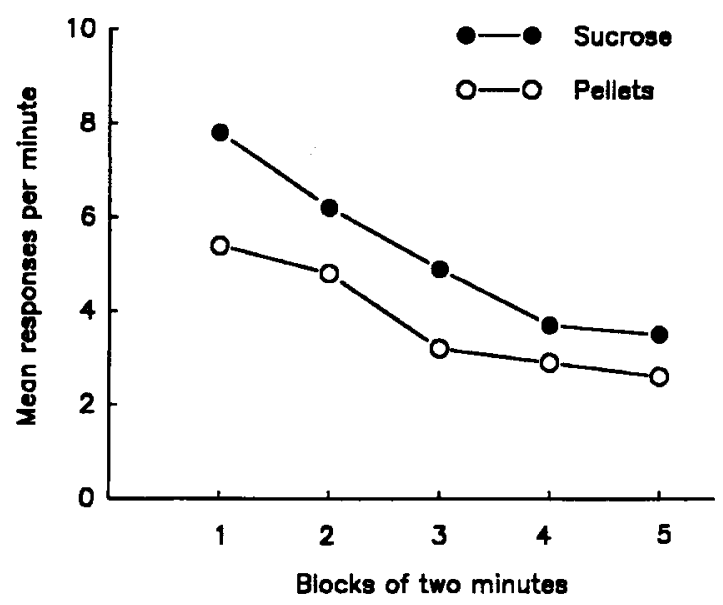

Figure 4. Experiment 2: Mean responses per minute during the first extinction test. The sucrose-trained (filled circles) and pellettrained (open circles) responses are plotted separately. All animals were tested under thirst. 


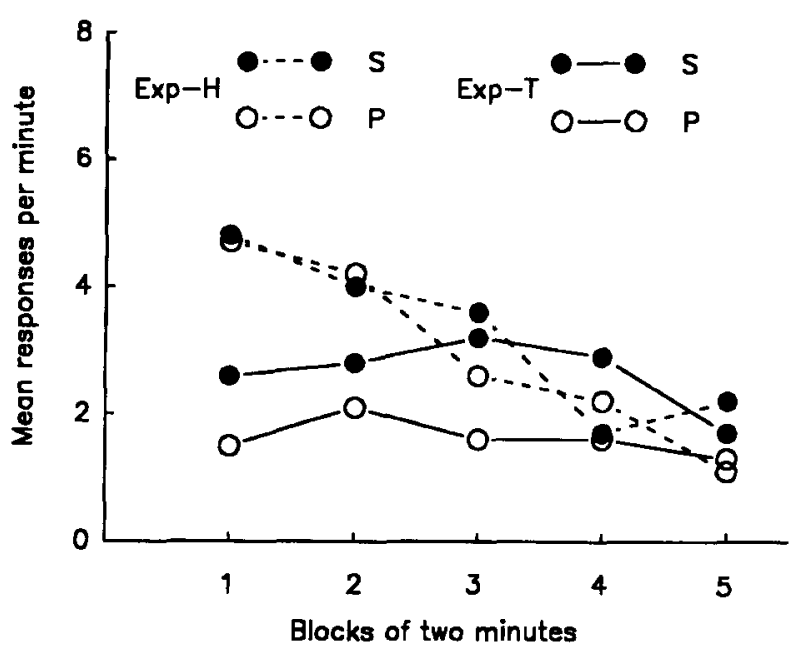

Figure 5. Experiment 2: Mean responses per minute during the extinction test conducted under thirst for subjects exposed to sucrose while thirsty (Group Exp-T) and for subjects exposed to sucrose while hungry (Group Exp-H). The sucrose-trained (S, filled circles) and pellet-trained (P, open circles) responses are shown separately.

difference between the mean sucrose preference ratios for Group Exp-T (.56) and Group Exp-H (.55).

These data provide only weak support for the view that exposure to sucrose under thirst produces a stronger preference for the sucrose-trained response. Of particular concern is the direction of the difference in overall levels of sucrose-trained responses during testing. If exposure to sucrose under the test drive state contributed more accurate information about the value of sucrose, Group Exp-T should have responded more, rather than less, than Group Exp-H on the sucrose-trained response. However, the relatively lower level of sucrose-trained responses in Group Exp-T would be expected if, during the exposure phase, Group Exp-T was learning that consumption of sucrose under thirst was increasing rather than reducing their state of dehydration. That possibility seems unlikely for two reasons. First, the present studies employed a less concentrated sucrose solution ( $8 \%$ ) than the one used by Dickinson and Dawson (1988). In their study, experience with a $20 \%$ sucrose solution induced a sucrose-response preference in thirsty rats. Second, there was no difference between Groups Exp-T (5.6 responses/min) and Exp-H (5.5 responses/min) in the rate of responding for sucrose during the final, reacquisition test. Had Group Exp-T learned that sucrose did not satisfy their thirst, they should have responded less than Group Exp-H. Incidentally, both groups displayed a significant sucrose-response preference during this reacquisition test, which further confirmed the success of the drive shift in enhancing the attractiveness of sucrose relative to pellets. The mean rate of responding for pellets was 4.4 responses/min in Group Exp-H $[T(16)=$ $27, p<.05]$ and 2.9 responses/min in Group Exp-T $[T(16)=6, p<.01]$.
A more likely explanation for the difference in the sucrose-trained response during testing is that the noncontingent sucrose presentations elicited a response, such as magazine tending, that became conditioned to the context and, more importantly, to the current drive state. During testing under thirst, this competing response would be evoked more strongly in Group Exp-T than in Group Exp-H, and would thus interfere more with the instrumental performance of Group Exp-T. This argument is reinforced by the direction of the difference in the levels of pellet-trained responding between the two groups.

Thus, it is possible that Experiment 2 may not have provided an optimal test of the effect of experience with the new value of an outcome on instrumental performance. This issue was readdressed in Experiment 3 using a design in which the likelihood of differential competing responses was minimized.

\section{EXPERIMENT 3}

The previous two expcriments suggest that instrumental responses can be affected by a change in the value of their consequences without experience of that new value. Experiment 3 was designed to strengthen these findings and to investigate further the effect of exposure to the revalued outcome on instrumental performance.

The present results have been described in terms of the view that thirst increases the attractiveness of the sucrose reinforcer relative to pellets. However, other accounts of these data are plausible. It is well known that any change between the conditions of training and testing may disrupt responding. To the degree that pellets were a less effective reinforcer than sucrose, the pellettrained response might be more vulnerable to the decremental effect of shifting drive states between training and testing. If this were the case, any manipulation that introduced a difference between training and test conditions should interfere more with the pellet-trained response and thus produce a preference for the sucrosetrained response. Thus, one purpose of Experiment 3 was to examine the specificity of the sucrose-response preference to thirst. To this end, Experiment 3 tested responding under both higher and lower levels of hunger drive than that employed in original training. According to the generalization decrement account, such manipulations should yield a sucrose-response preference. On the other hand, if thirst changes the relative merits of sucrose and pellets, changes in the amount of hunger should not induce a sucrose-response preference.

The other purpose of Experiment 3 was to explore further the role of experience with the outcome under the test drive state. In Experiment 2, assessment of the effect of that experience on the sensitivity of the instrumental response to the revalued outcome was complicated by the problem of differential competing responses. There are several ways to minimize this problem. One solution involves retraining the original responses after the ex- 


$\begin{array}{ccccc}\text { Training } & \text { Test } & \text { Test } & \text { Exposure } & \text { Test } \\ \text { (Hunger) } & \text { (Hunger) } & \text { (Thirst) } & \text { (Sucrose) } & \text { (Thirst) }\end{array}$

\begin{tabular}{|c|c|c|c|c|c|c|c|}
\hline $\begin{array}{l}\text { R1 } \\
\text { R2 }\end{array}$ & $\begin{array}{l}->\text { Pellet } \\
->\text { Sucrose }\end{array}$ & $\begin{array}{r}30: \\
6:\end{array}$ & $\begin{array}{l}\text { RI } \\
\text { R3 }\end{array}$ & $\begin{array}{ll}v & R 2 \\
v & R 4\end{array}$ & $R 1 \vee R$ & $\begin{array}{l}\text { Thirst } \\
\text { R4 } \rightarrow \mathrm{S}\end{array}$ & \\
\hline $\begin{array}{l}\mathbf{R} 3 \\
\mathrm{R} 4\end{array}$ & $\begin{array}{l}\text {-> Pellet } \\
->\text { Sucroge }\end{array}$ & $\begin{array}{r}\text { 6: } \\
30:\end{array}$ & $\begin{array}{l}\text { R1 V } \\
\text { R3 }\end{array}$ & $\begin{array}{ll}v & R 2 \\
v & R 4\end{array}$ & $R 3 \vee R$ & $\begin{array}{l}\text { Hunger } \\
\text { R4 } \rightarrow \text { s }\end{array}$ & \\
\hline
\end{tabular}

Figure 6. Basic design of Experiment 3: R1, R2, R3, and R4 are instrumental responses (leverpress, chain pull, nose poke, and handle pull); 30 and 6 indicate the number of hours of food deprivation.

posure phase until any between-group difference is overcome. With one exception (Dickinson \& Dawson, 1989, Experiment 1B), this strategy has been used routinely by Dickinson and his colleagues. Such a solution, however, prohibits evaluation of the exposure treatment on previously acquired response-outcome associations. An alternative strategy is to prevent the development of the competing response during the exposure phase. A convenient method for accomplishing this is to arrange for the sucrose presentations to be response contingent. Thus, in Experiment 3, subjects were required to perform an instrumental response for the sucrose during the exposure phase. This response was then removed during the critical tests, thus prohibiting any differential interference with the target instrumental responses. In this way, the effect of experience with the revalued outcome could be assessed on previously established instrumental associations.

Figure 6 illustrates the basic design of Experiment 3 . Two pairs of responses were trained, the leverpress and the chain pull, and the nose poke and the handle pull. Within each pair, one response earned sucrose and the other earned pellets. To assess the specificity of the sucrose preference to a thirsty drive state, each of these pairs was tested in extinction under an increased $(30 \mathrm{~h}$ food deprived) and a decreased ( $6 \mathrm{~h}$ food deprived) hunger drive. These tests did not reveal any evidence of a preference for the sucrose response. To confirm that a shift to thirst would induce a sucrose-trained response preference, both response pairs were tested while the animals were thirsty. A significant sucrose-response preference was obtained. Following these tests, the drive states of the subjects were alternated between hunger and thirst. Half of the animals were given the opportunity to earn sucrose on days when they were thirsty, while the remaining subjects earned sucrose on days when they were hungry. To assess whether experience with the sucrose under thirst affected subsequent instrumental performance, all animals were given a final extinction test while thirsty.

\section{Method}

\section{Subjects and Apparatus}

Sixteen experimentally naive male Holtzman-derived SpragueDawley rats (Harlan Co.) served as subjects. They were housed in individual cages with ad-lib access to water. Food was available for $1 \mathrm{~h}$ every day. The apparatus was the same as that used in the previous studies.

\section{Procedure}

Magazine training and CRF training of the four instrumental responses followed the procedure described in Experiment 1. Each response was then trained on a VI $30-\mathrm{sec}$ schedule for two 20 -min sessions. There was one session per day. The order of training for the first four sessions was lever, chain, nose poke, handle pull; this order was reversed for the second four sessions. As in Experiment 1 , there were five 20-min sessions of concurrent VI training with the lever and chain intermixed with five 20 -min sessions of concurrent VI training with the nose-poke and handle-pull responses. The details of this training were the same as those reported for Experiment 1.

Testing. Each animal received two choice extinction tests, one with the lever and chain and one with the nose poke and handle pull. Each extinction test lasted $10 \mathrm{~min}$ and contained no reinforcers. One of the tests was conducted at $6 \mathrm{~h}$ of food deprivation and the other at $30 \mathrm{~h}$ of food deprivation. The order of testing and the particular response pair tested under the different levels of deprivation were balanced across animals.

All subjects were then shifted to thirst and given two 10-min extinction tests. The first test contained the nose-poke and handlepull manipulanda; the second test contained the lever and chain manipulanda. No reinforcers were available in these tests.

Exposure. This phase was identical to that in Experiment 2 with one exception: Instead of receiving sucrose on a VT $60-\mathrm{sec}$ schedule, the subjects earned the sucrose reinforcer on a VI 60-sec schedule. The response available in these sessions was either the nose poke or the handle pull, whichever had been trained with the sucrose outcome. These sessions terminated after $20 \mathrm{~min}$. As in Experiment 2, half the subjects received the sucrose exposure on days they were thirsty $(\mathrm{Exp}-\mathrm{T})$ and half received exposure on days they were hungry $(\mathrm{Exp}-\mathrm{H})$.

Testing. Thirst was induced in all subjects at the end of the last sucrose-exposure session. The next day, a 10-min choice extinction test with the lever and the chain was administered. To assess the effectiveness of the thirst-induction technique, a 20 -min reacquisition session was given to all subjects after completion of extinction testing. Both the lever and chain manipulanda were available in that session. Responding on each was reinforced on separate VI 60 -sec schedules with the outcomes used to train those responses.

\section{Results and Discussion}

The four responses were trained successfully. In the final session of concurrent VI training, the mean rate of responding combined across response pairs was 13.1 responses $/ \mathrm{min}$ for pellets and 9.8 responses $/ \mathrm{min}$ for sucrose. This difference was significant $[T(16)=22$, $p<.05]$. 
The results of the choice extinction tests conducted under different levels of food deprivation are summarized in Figure 7 in blocks of 2 min. Responding established with either the pellet outcome (open circles) or the sucrose outcome (filled circles) is shown separately when the animals were $6 \mathrm{~h}$ food deprived (solid lines) and when they were $30 \mathrm{~h}$ food deprived (dashed lines). Not surprisingly, increasing food deprivation produced higher response rates. The important finding, however, is that variations in the level of food deprivation did not produce a preference for the sucrose response. At neither food-deprivation level did the animals display a significant preference for the response trained with sucrose. If anything, the animals continued to show, albeit rather marginally, a preference for the pellet-trained response. A Friedman two-way analysis of variance by ranks was used to compare performance under the four conditions. A significant effect was obtained $(F r=29.87, d f=3$, $p<.01)$. The significance of individual pairs of differences was tested using a procedure described by Siegel and Castellan (1988). Neither increasing ( $30 \mathrm{~h}$ ) nor decreasing $(6 \mathrm{~h})$ food-deprivation levels produced a significant preference for the sucrose-trained response; neither difference exceeded the value of the critical difference (19.26). However, response rates under $30 \mathrm{~h}$ of food deprivation were significantly higher than those under $6 \mathrm{~h}$ of food deprivation; all differences exceeded the value of the critical difference $(19.26, p<.05)$. The latter result is consistent with other work using comparable fooddeprivation levels to manipulate hunger (e.g., Crocetti, 1962; Davidson, 1987).

The results of the choice extinction tests administered when the animals were thirsty are shown in Figure 8. Rates of responding were combined for the responses trained with the same outcome and shown in blocks of

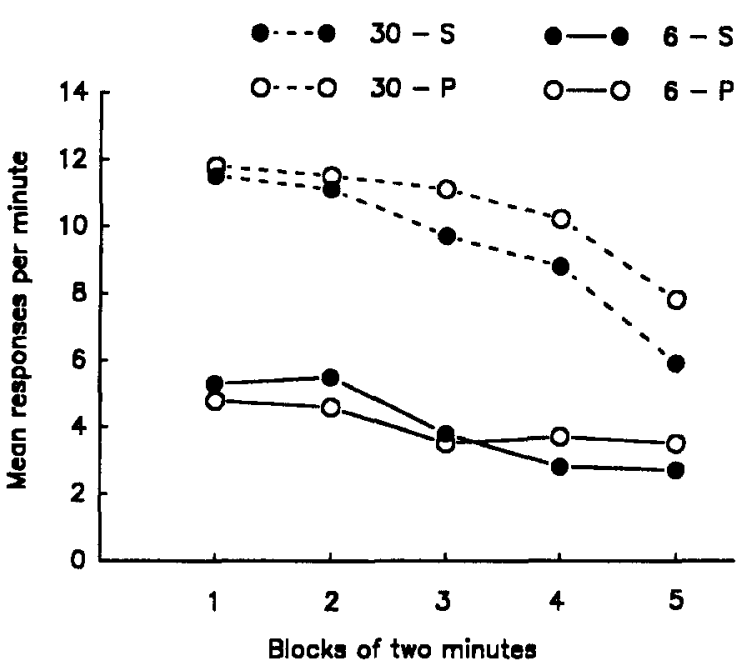

Figure 7. Experiment 3: Mean responses per minute during extinction testing. The sucrose-trained ( $S$, filled circles) and pellettrained ( $P$, open circles) responses are shown separately when the subjects were either $6 \mathrm{~h}$ (solid line) or $30 \mathrm{~h}$ (dashed lines) food deprived.

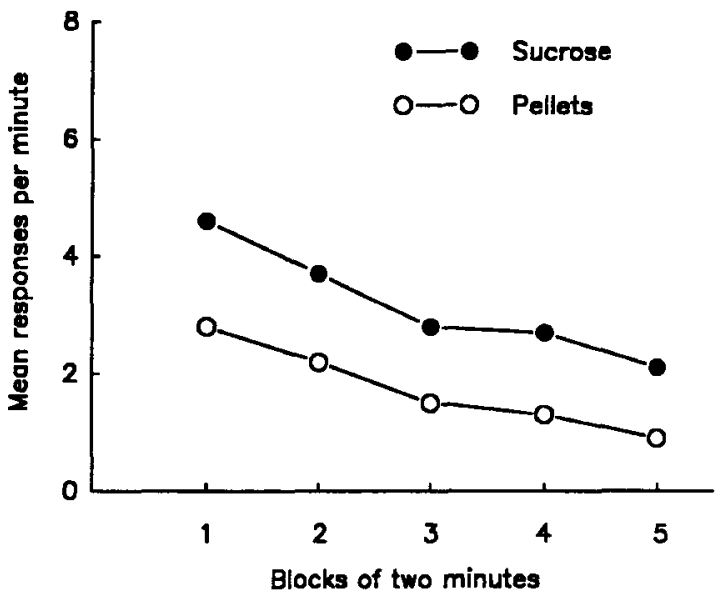

Figure 8. Experiment 3: Mean responses per minute during the first extinction test. The sucrose-trained (filled circles) and pellettrained (open circles) responses are plotted separately. All animals were tested under thirst.

$2 \mathrm{~min}$. There was an overwhelming preference for the sucrose response throughout testing $[T(16)=1, p<.01]$. This result replicates the findings of the previous experiments that changes in the value of an outcome need not be experienced in order to influence instrumental performance.

The present findings are important for two reasons. First, the observation of a significant sucrose response preference under thirst rules out variations in the fooddeprivation regime as an account of the discrepancy between the results of Experiments 1 and 2 and those reported by Dickinson and his colleagues. Dickinson and Dawson $(1987,1988,1989)$ induced hunger by allowing subjects access to food for $1 \mathrm{~h}$ per day. However, use of this food-deprivation procedure in Experiment 3 produced results similar to those of Experiments 1 and 2, in which hunger was induced by restricting food intake on a daily basis such that the subjects were maintained at $80 \%$ of their ad-lib weights. Second, the failure of variations in the level of hunger deprivation to induce a sucrose-response preference emphasizes the dependence of the sucrose-response preference on a shift to thirst. That specificity suggests that the preference is not a product of differences in the vulnerability of sucrose- and pellet-trained responses to generalization decrement brought about by the change in drive conditions between training and testing. Instead, the specificity suggests that, under thirst, the value of the sucrose outcome is enhanced relative to the pellet outcome.

Figure 9 shows the responses made during the extinction test given after exposure to sucrose under either thirst (solid lines) or hunger (dashed lines) plotted in blocks of $2 \mathrm{~min}$. These responses are shown separately for sucrose (filled circles) and pellets (open circles). Consider first responding in the animals who had been exposed to sucrose hungry (Exp-H). Although there was some evidence of a preference for the response trained 


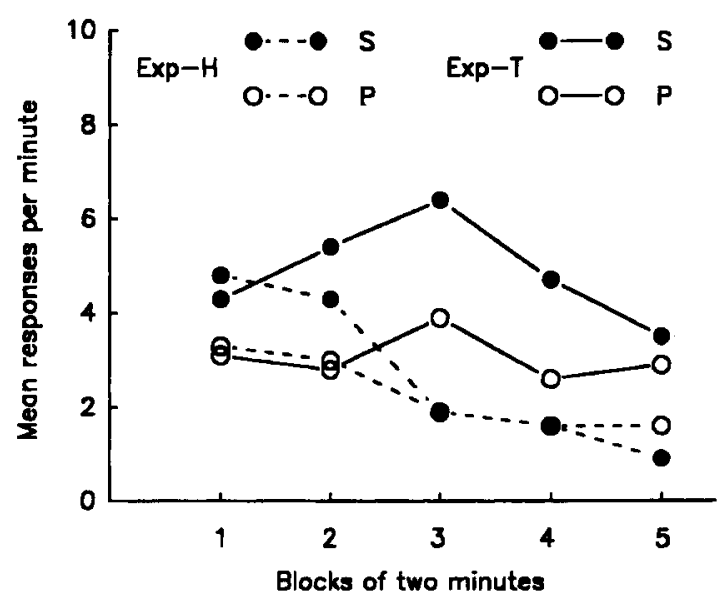

Figure 9. Experiment 3: Mean responses per minute during the extinction test conducted under thirst for subjects exposed to sucrose while thirsty (Group Exp-T) and for subjects exposed to sucrose while hungry (Group Exp-H). The sucrose-trained (S, filled circles) and pellet-trained (P, open circles) responses are shown separately.

with sucrose at the start of the test in Group Exp-H, this preference disappeared over the course of testing as responding rapidly extinguished. Analysis of the test session as a whole revealed no significant difference between pellet-trained and sucrose-trained responses. Inspection of Figure 9 also shows an initial preference for the sucrose-trained response in the group exposed thirsty (Group Exp-T). However, that preference appears much larger and persists throughout the test session $[T(8)=4, p=.05]$.

Additional analyses of these data revealed significantly more sucrose-trained responses in Group Exp-T than in Group Exp-H [Mann-Whitney $U(8,8)=5.5, p<$ $.05]$ but no significant difference in the rate of pellettrained responses. Sucrose-preference ratios were calculated for Group Exp-T (.66) and Group Exp-H (.54) but found to be not statistically different. In summary, these findings suggest that exposure to sucrose while thirsty produced a slightly stronger preference for the sucrose response during a test conducted under thirst.

The results of the reacquisition session administered under thirst confirmed that the thirst-induction procedure was successful in increasing the value of the sucrose outcome relative to the pellet outcome. For Group Exp-T, the mean rate of sucrose-trained responding (6.4 responses/min) was significantly higher than pellettrained responding (3.7 responses $/ \mathrm{min}$ ) $[T(8)=4, p<$ $.05]$. A similar result was found for Group Exp-H; the mean rate of sucrose-trained responding (6.4 responses/ $\mathrm{min}$ ) was significantly higher than pellet-trained responding (4.3 responses $/ \mathrm{min})[T(8)=1, p<.05]$.

\section{GENERAL DISCUSSION}

The results of these experiments suggest that an instrumental response can be sensitive to a change in the value of its outcome when no opportunity to experience that new value is provided. In all three studies, animals trained to make one response for sucrose and another response for pellets when hungry showed a substantial and significant preference for the sucrose response during extinction tests conducted while they were thirsty. This preference for the sucrose-trained response was not exhibited during initial training or during extinction tests conducted under hunger.

Experiment 3 further showed that this sucroseresponse preference was not a general consequence of altering the drive conditions between training and testing. Testing under either increased or decreased levels of food deprivation did not yield a preference for the sucrosetrained response. These data imply that the thirst-induced sucrose-response preference cannot be explained in terms of differential susceptibility of the pellet and sucrose responses to generalization decrement. Moreover, the results of Experiment 3 permit rejection of the possibility that the preference for the sucrose response is a consequence of simply reducing general levels of responding. Both the procedure to induce thirst and the procedure to reduce hunger resulted in fewer overall responses. However, only under thirst was there any evidence of a preference for the sucrose-trained response.

The finding that instrumental performance may be affected directly by a change in the value of the instrumental outcome is consistent with several other observations. Dickinson and Balleine (1990) used a shift from thirst to hunger to enhance the merits of sucrose relative to saline during testing. They found that animals trained to make one response for sucrose and another for saline when thirsty showed a preference for the sucrose response when tested under hunger. Rescorla $(1992,1994)$ found that devaluation of an outcome produced by a single pairing of that outcome with a toxin might also have an immediate effect in reducing performance of an instrumental response trained with that outcome. Although unable to detect this kind of immediate effect on explicitly trained instrumental responses, Balleine and Dickinson (1991) did find that magazine responses were depressed by a single pairing of the outcome with a toxin.

For each of these results, however, an alternative interpretation has been offered, albeit with varying degrees of success, that preserves the basic idea that an instrumental response remains unaffected by a change in the value of its outcome until experience with the revalued outcome is arranged (see Dickinson \& Balleine, 1994). Furthermore, it is not impossible to reconcile our finding of a direct effect of outcome revaluation on instrumental performance with the general thesis proposed by Tolman (1949a, 1949b) and by Dickinson and his colleagues (e.g., Dickinson, 1989; Dickinson \& Balleine, 1994). Throughout our studies, water was freely available to the animals in their home cage. It seems likely, however, that the animals drank that water only when they were thirsty. Consequently, they had repeated opportunities to learn about the value of water under thirst. To the degree that water and the $8 \%$ sucrose solution used in our experiments were not completely discriminated, a 
direct effect of revaluation of the sucrose outcome on instrumental performance could have been mediated by generalization from the learned value of water under thirst. Moreover, as the likelihood of generalization between water and sucrose is reduced by increasing the concentration of sucrose, exposure to sucrose under thirst would become increasingly necessary for producing a change in instrumental performance. Thus, this generalization account offers a potential explanation for the discrepancy between our results and those from Dickinson's laboratory, which used a $20 \%$ sucrose solution.

The issue of whether exposure to the outcome after its value has been changed increases the sensitivity of the response to that value is more difficult to assess in our experiments. In both Experiment 2 and Experiment 3, it was difficult to detect a reliable increase in the magnitude of the sucrose-response preference following exposure to sucrose under thirst. We have already considered various procedural factors that might have accounted for that difficulty. It is also worth noting that prior extinction testing of the responses may have further undermined our ability to detect a significant enhancement of the sucrose preference.

What is not addressed by the present experiments is the question of why exposure to the revalued outcome affects subsequent instrumental performance. Dickinson and his colleagues (see Dickinson \& Balleine, 1994) have argued that exposure to the revalued outcome enables the formation of a connection between that outcome and the accompanying motivational state. This incentive learning is assumed to be crucial for producing a change in performance of an instrumental response associated with the outcome.

But exposure to the revalued outcome may alter instrumental performance for a reason other than incentive learning. For example, in drive-shift studies, the exposure treatments may produce differential expectations about the availability of the outcomes under particular drive states. Thus, animals exposed to sucrose under thirst may have learned only that sucrose was more likely to be available than were pellets when they were thirsty. As a result, it is not surprising that when tested under thirst, extinction of the sucrose-trained response proceeds more slowly than that of the pellet-trained response. The merits of this argument might be assessed by an examination of the relative rates of extinction of sucrose- and pellettrained responses under hunger in animals given exposure to sucrose under hunger. To match overall response rates, such extinction should ideally be conducted under a low level of food deprivation. If the sucrose-trained response extinguished more slowly under these test conditions, it would make interpretation of the effects of exposure to sucrose under the thirst-drive state substantially more complicated.

In conclusion, these studies demonstrate that instrumental responses can be sensitive to shifts in the value of their outcomes even in the absence of experience with those changed values. The range of circumstances under which an immediate effect of drive shifts on instrumental performance will be obtained, as in the present studjes, and the conditions under which investigators will fail to find such an effect, as in the work by Dickinson and his colleagues, remain to be specified. What is apparent, however, is that application of the principles espoused by Tolman (1949a, 1949b) and Dickinson (1989) for the impact of drive shifts on instrumental performance may be constrained by parameter values.

\section{REFERENCES}

ADAms, C. D., \& Dickinson, A. (1981). Instrumental responding following reinforcer devaluation. Quarterly Journal of Experimental Psychology, 33B, 109-121.

BALLEINE, B. (1992). Instrumental performance following a shift in primary motivation depends upon incentive learning. Journal of Experimental Psychology: Animal Behavior Processes, 18, 236-250.

BALLEINE, B., \& DiCKINSON, A. (1991). Instrumental performance following reinforcer devaluation depends upon incentive learning. Quarterly Journal of Experimental Psychology, 43B, 279-296.

Colwill, R. M., \& Rescorla, R. A. (1985). Postconditioning devaluation of a reinforcer affects instrumental responding. Journal of Experimental Psychology: Animal Behavior Processes, 11, 120-132.

Colwill, R. M., \& Rescorla, R. A. (1986). Associative structures in instrumental learning. In G. H. Bower (Ed.), The psychology of learning and motivation (Vol. 20, pp. 55-104). New York: Academic Press.

Crocetti, C. P. (1962). Drive level and response strength in the barpressing apparatus. Psychological Reports, 10, 563-575.

DAvidson, T. L. (1987). Learning about deprivational intensity stimuli. Behavioral Neuroscience, 101, 198-208.

Dickinson, A. (1989). Expectancy theory in animal conditioning. In S. B. Klein \& R. R. Mowrer (Eds.), Contemporary learning theories: Pavlovian conditioning and the status of traditional learning theory (pp. 279-308). Hillsdale, NJ: Erlbaum.

Dickinson, A., \& Balleine, B. (1990). Motivational control of instrumental performance following a shift from thirst to hunger. Quarterly Journal of Experimental Psychology, 42B, 413-429.

Dickinson, A., \& Balleine, B. (1994). Motivational control of goaldirected action. Animal Learning \& Behavior, 22, 1-18.

Dickinson, A., \& DAwson, G. R. (1987). The role of the instrumental contingency in the motivational control of performance. Quarterly Journal of Experimental Psychology, 39B, 77-93.

Dickinson, A., \& Dawson, G. R. (1988). Motivational control of instrumental performance: The role of prior experience of the reinforcer. Quarterly Journal of Experimental Psychology, 40B, 113-134.

Dickinson, A., \& Dawson, G. R. (1989). Incentive learning and the motivational control of instrumental performance. Quarterly Journal of Experimental Psychology, 41B, 99-112.

Dickinson, A., \& Nicholas, J. (1983a). Irrelevant incentive learning during training on ratio and interval schedules. Quarterly Journal of Experimental Psychology, 35B, 235-247.

DiCKINSON, A., \& Nicholas, J. (1983b). Irrelevant incentive learning during instrumental conditioning: The role of the drive-reinforcer and response-reinforcer relationships. Quarterly Journal of Experimental Psychology, 35B, 249-263.

KHAVARI, K. A., \& EISMAN, E. H. (1971). Some parameters of latent learning and generalized drive. Journal of Comparative \& Physiological Psychology, 77, 463-469.

KRIECKHAUS, E. E., \& WolF, G. (1968). Acquisition of sodium by rats: Interaction of innate mechanisms and latent learning. Journal of Comparative \& Physiological Psychology, 65, 197-201.

Rescorla, R. A. (1982). Comments on a technique for assessing associative learning. In M. L. Commons, R. J. Herrnstein, \& A. R. Wagner (Eds.), Quantitative analysis of behavior (Vol. 3, pp. 427-452). New York: Appleton-Century-Crofts.

RESCORLA, R. A. (1990). Instrumental responses become associated 
with reinforcers that differ in one feature. Animal Learning \& Behavior, 18, 206-211.

Rescorla, R. A. (1992). Depression of an instrumental response by a single devaluation of its outcome. Quarterly Journal of Experimental Psychology, 44B, 123-136.

Rescorla, R. A. (1994). A note on depression of instrumental responding after one trial of outcome devaluation. Quarterly Journal of Experimental Psychology, 47B, 27-37.

SiEGEl, S., \& CASTEllan, N. J., JR. (1988). Nonparametric statistics for the behavioral sciences (2nd ed.). New York: McGraw-Hill.
TATE, M. W., \& Clelland, R. C. (1957). Nonparametric and shortcut statistics in the social, biological and medical sciences. Danville, IL: Interstate Printers \& Publishers.

Tolman, E. C. (1949a). The nature and functioning of wants. Psychological Review, 56, 357-369.

Tolman, E. C. (1949b). There is more than one kind of learning. Psychological Review, 56, 144-155.

(Manuscript received August 13, 1991; revision accepted for publication January 17,1995 .) 